\title{
We walk together (2020)
}

\author{
Rui Chaves, Eduardo Patrício, Laura Romero, Lilian Nakahodo, Luz da Camara \\ Federal University of Paraíba | Brazil
}

Bydgoszcz Music Academy | Poland
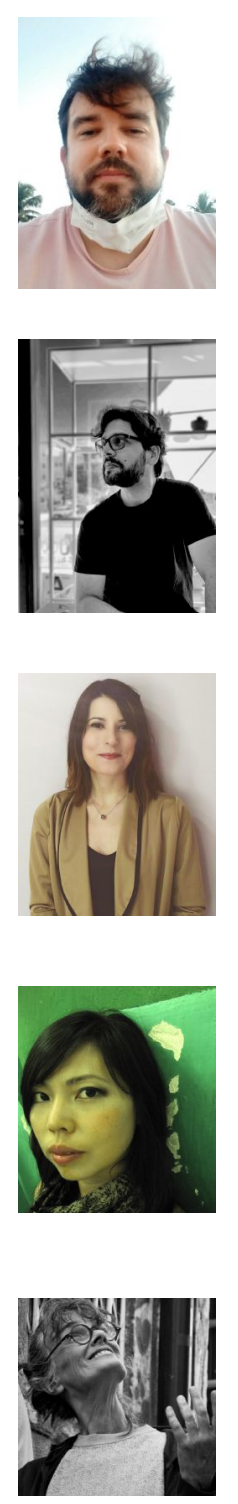

Rui Chaves is a sound artist, curator and researcher. From 2015-2018, he was a postdoctoral researcher at NuSom (University of São Paulo) with a project focusing on creating an online 'archive' of Brazilian sound art. In 2019, he co-edited with Professor Fernando Iazzetta the volume Making it Heard: A History of Brazilian Sound Art. Currently, he is a visiting lecturer at the Federal University of Paraíba visual arts department (2020-2024). E-mail: rui.chaves@gmail.com

Eduardo Patrício is an assistant professor at the Bydgoszcz Music Academy. Sound designer focused on spatial sound, immersive media (VR / AR / XR), and sound to picture. Eduardo has a diverse background in research and music composition. More specifically, his interests lie on interactivity, post-production, and spatiality as mediators of rich and personal sonic experiences.

Laura Romero. Audio producer, radio-maker, professor and researcher, she loves to create projects in different languages and territories, working for universities, media, podcast and radio stations. Her work is based on the intimacy and poetry of sound as a powerful tool to tell stories and preserve memories. Strongly interested in documentary field and the confluence of audio artistic works in a multilingual space. $\mathrm{PhD}$ in Communication, freelance researcher and professor.

Lilian Nakahodo is an independent artist-researcher, with an emphasis on contemporary sonic practices. She also works as a musician (pianist, composer and bedroom producer) and audiovisual sound editor. Since 2015, she has performed sound walks for a diverse range of audiences in the context of the Mapa Sonoro de Curitiba project (Fundação Cultural de Curitiba, 2015).

Luz da Camara is a homeless body in search of herself by fleeing a binary logic. My research is about the production of atmospheres understood as the moment immediately before the split between subject and object. Works on and off with sound since 1995. I am a member of cem - centro em movimento (www.ce-m.org) since 1998. Amongst other things, writes about walking journeys. Lives between Lisbon and Alentejo. 
e walk together (2020) is a 'field-recording' score that asks would-be performers to think sonically about a place, to produce sounds with and within their surround environment. To chart a shared map between would-be performers and end-listeners ${ }^{1 .}$

FIGURE 1 - Eduardo Patrício recording in Koziegłowy (Poland).

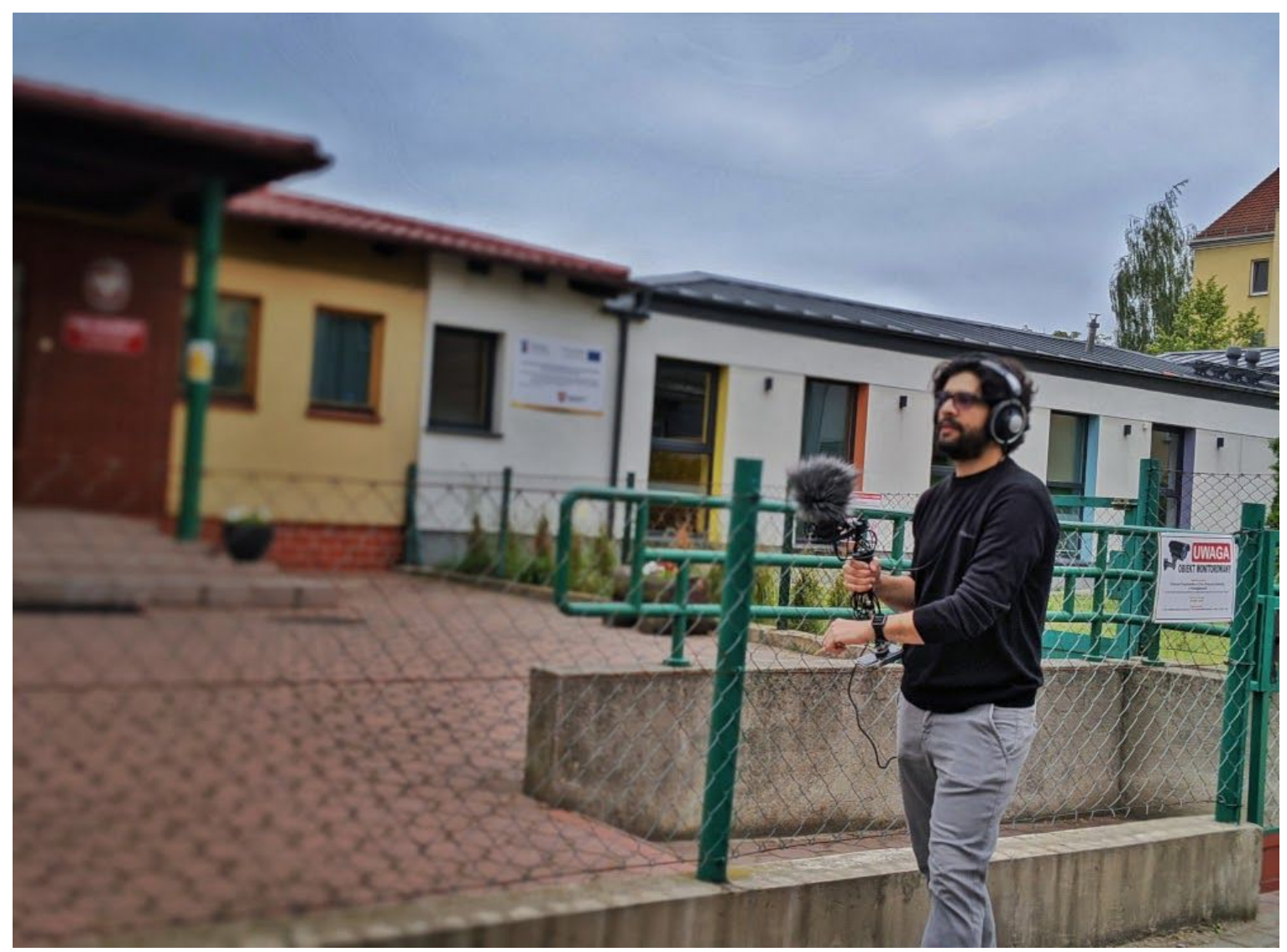

Source: Eduardo Patrício (2020)

\footnotetext{
${ }^{1}$ This collaborative endeavour is a continuation of Chaves' work with curatorial approaches to sound artwork outside of institutional frameworks See '32 instruçôes para escutar n(a) pandemia' (CHAVES \& IAZZETTA, 2021).
} 
FIGURE 2 - We walk together score

\section{We walk together}

Design a walk that lasts 25 minutes. If possible, try to stay close to entries to indoor places. Bring a drumstick with you. In the walk, encompass soundmarks of the surrounding area where you live. Include routes that go from very loud to very quiet areas. Try to pass by spaces that have interesting acoustics. Try to follow the below actions in order and use a stopwatch. At the beginning of the recording, say 'start'. If possible make short videos during the walk. Ask other people to record. Sync the recordings.

- Walk for a bit (0'00" - 3'00")

- Say the time (hh:mm and then $\mathrm{dd} / \mathrm{mm} / \mathrm{yy}$ ), your name, where you are, describe what you see and then what you listen. How do you feel about it? $\left(3^{\prime} 00 "-8^{\prime} 00 "\right)$

- Walk and whistle or sing (8'00" - 10'00")

- Scratch something (wall, railings, floor) with your drumstick while you walk (10'00" - 13'00")

- Go indoors (This might take a while, use the five minutes to get in and out to prepare for the next action) (13'00"-18'00")

- Walk and finish in your home. While performing this action, play a percussion pattern $\left(18^{\prime} 00-21^{\prime} 00^{\prime}\right)^{*}$

- Talk about whatever you want or just stay silent. (21'00" 25 '00")

* This pattern might be informed by some kind of material or architectural repetition present in the cityscape.

Source: Rui Chaves (2021)

This version of we walk together was recorded in 2020. The resulting piece is a multi-layered and multilinguistic 'sequence shot': a binaural audio piece that straddles the line between fiction, documentary and musical composition. The participating artists were located in different parts of the globe: Rui Chaves (Loulé, Portugal, 25/06/2020), Eduardo Patrício (Koziegłowy, Poland, 17/06/2020), Laura Romero (Valencia, Spain, 06/06/2020), Lilian Nakahodo(Curitiba, Brazil, 05/07/2020), Luz da Camara (Évoramonte, Portugal, 19/06/2020). 
FIGURE 3 - Igreja Matriz de São Clemente (Loulé, Portugal)

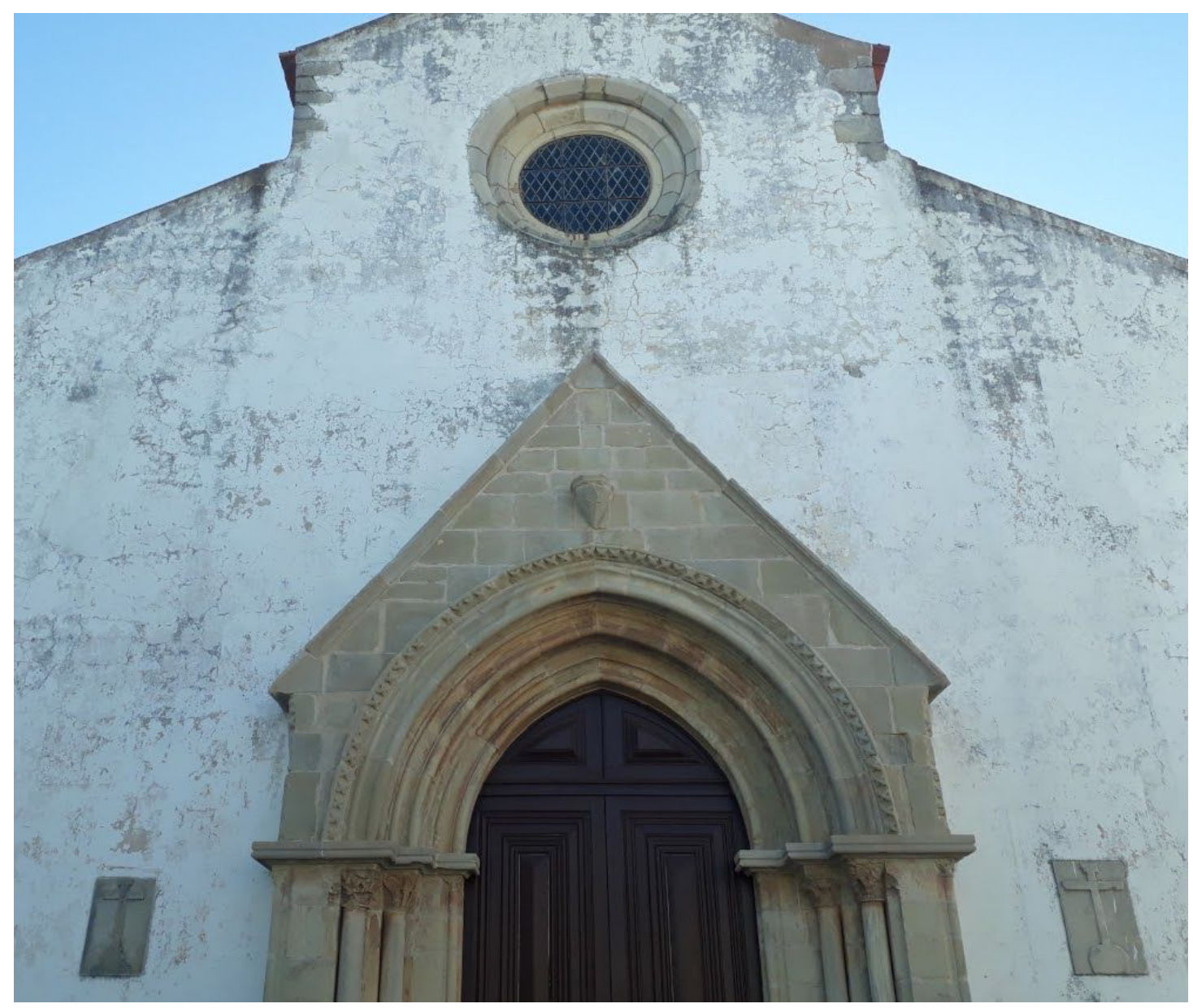

Source: Rui Chaves (2020) 


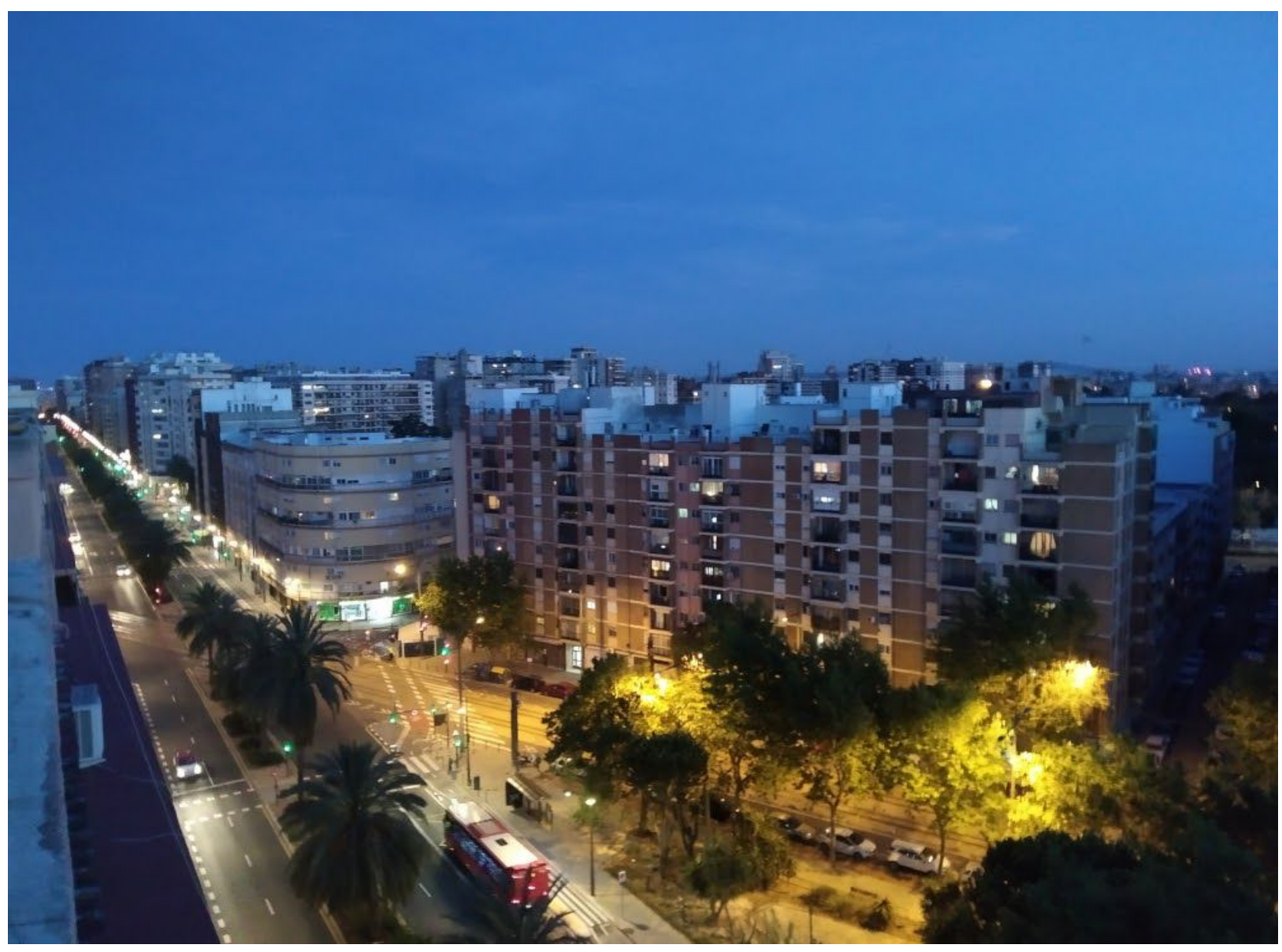

Source: Laura Romero (2020) 
FIGURE 5 - Lilian Nakao Nakahodo recording in Curitiba (Brazil)

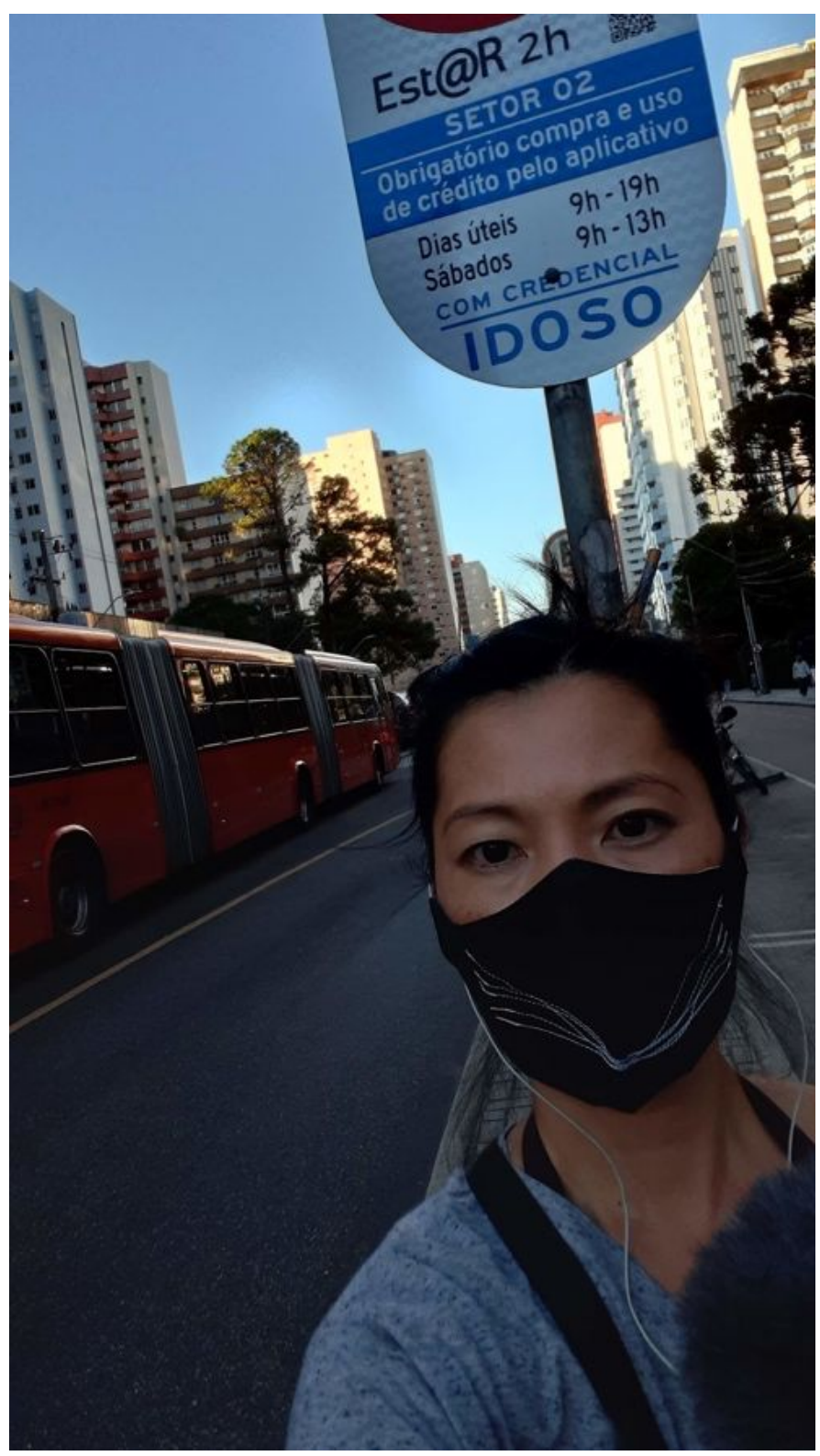

Source: Lilian Nakao Nakahodo (2020)

\section{REFERENCES}

CHAVES, Rui \& IAZZETTA, Fernando 32 Instruções Para Escutar (n)a Pandemia. São Paulo. BERRO, 2021. Available at: https://berro-nusom.bandcamp.com/merch/32-instru-es-para-escutar-n-a-pandemiapaperback-edition. Accessed on: 25 Oct. 2021. 